\title{
El incierto crecimiento económico colombiano
}

$\mathrm{U}$ no de los objetivos de política económica más importantes en cualquier país es el crecimiento económico. Su importancia radica en que si la producción aumenta, las rentas serán más altas mañana y las generaciones futuras alcanzarán mayores niveles de bienestar material. De igual manera, si crece la economía -manteniendo constante la estructura tributaria-, el Gobierno obtendrá mayores ingresos fiscales, dispondrá, por lo tanto, de más recursos para financiar un gasto social más elevado y, de esta forma, podrá combatir la pobreza y satisfacer una serie de necesidades básicas. Así mismo, si crece la economía, se aprovechan mejor los recursos productivos y, por consiguiente, el nivel de empleo se incrementa.

Algunas corrientes de pensamiento económico (keynesianos, neoclásicos, neoliberales, entre otros) conciben el crecimiento económico como si fuera desarrollo económico, y plantean que a medida que crece la economía, toda la población se beneficia, lo cual es discutible, más aún en economías como la colombiana donde la desigualdad tiende a persistir.

Si el desarrollo económico hace referencia al bienestar de la población, en el que deben estar presentes no solo los aspectos económicos, sino también, los sociales, los culturales, los políticos y, últimamente, los ambientales, entonces considerar el crecimiento como desarrollo es reducir un concepto multidimensional a lo meramente económico. Autores como Amartya Sen consideran que el desarrollo es "un proceso de expansión de las libertades reales de que disfrutan los individuos". Para el economista indio, las libertades humanas son las determinantes, y el crecimiento del producto nacional bruto o de las rentas personales es un medio muy importante para extender las libertades de que goza una población, pero no sintetiza el desarrollo.

En el caso colombiano, el crecimiento de la economía ha presentado en los últimos seis años un descenso: en 2011 creció en 6,6 por ciento y en 2016 cayó al 2 por ciento. Pero el descenso más notable comienza a partir del 2015 , cuando la economía creció 3,1 por ciento, lo que coincide con la caída pronunciada de los precios del petróleo: mientras en junio de 2014, el barril se cotizó en 115 dólares la variedad Brendt (referencia para Colombia), en marzo de 2015 el precio se desplomó a 55 dólares, incluso, el 28 de enero de 2016 el crudo bajó a 44,4 dólares el barril. De hecho, a partir del 2012, también se reduce el precio de otros commodities, posible explicación del descenso de la tasa de crecimiento de los países latinoamericanos, que el año pasado fue de menos 1.4 por ciento.

Para el primer trimestre del presente año, la economía colombiana creció 1,1 por ciento, ritmo inferior a las previsiones realizadas por el Gobierno, que esperaba lo hiciera en 1,3 por ciento, cifra preocupante si la comparamos con el mismo período del 2016, cuando el producto interno bruto (PIB) tuvo un crecimiento de 2,7 por ciento. Lo anterior llevó a que las proyecciones 
de la evolución de la actividad económica para 2017 fueran ajustadas hacia abajo: el Banco Mundial (BM) la estimó en 2,5 por ciento y la disminuyó a 2 por ciento; el FMI, de 2,5 por ciento la fijó en 2,3 por ciento; el Banco de la República la redujo de 2 por ciento a 1,8 por ciento, y el Gobierno nacional, también, la bajó de 2,5 por ciento a 2,3 por ciento.

El descenso del PIB para los tres primeros meses del presente año se le atribuye a varios factores, tales como: a) el precio del petróleo, si bien ha subido un poco, sigue siendo bajo en comparación con el existente al iniciar el 2015 (el 31 de mayo del año en curso se ubicó en 50,3 dólares el barril); b) la reforma tributaria aprobada en diciembre del 2016 subió el impuesto al valor agregado (IVA) del 16 al 19 por ciento; dicho incremento afectó el precio de un número considerable de bienes y servicios, presionando a los consumidores a comprimir su demanda, ante la pérdida de su capacidad adquisitiva; c) el alza de la tasa de interés por parte del Banco de la República, con el fin de controlar la inflación: el costo del dinero pasó de 4,5 por ciento el 18 de agosto del 2015 al 7,75 por ciento en junio de 2016. De igual forma, el emisor mantuvo altas las tasas de interés hasta diciembre del año pasado, lo cual afectó negativamente tanto al sector industrial como al comercio, y, por último, el fuerte verano que soportó el país -sobre todo en el primer semestre del año 2016- redujo la oferta agrícola no solo de alimentos, sino también de materias primas esenciales para la industria.

El Gobierno nacional, para contrarrestar el bajo dinamismo del PIB, adoptó desde 2015 una serie de medidas de choque, con el fin de reactivar la producción. La primera fue el Plan de Impulso a la Productividad y el Empleo (Pipe), en sus dos versiones, el cual se orienta a impulsar la inversión pública en infraestructura y vías, estímulos al sector agropecuario y una mejor utilización de las regalías. Así mismo, programas para reactivar los sectores industrial, minero-energético, turismo y comercio. Además de los planes PIPE I y II, una vez conocido el bajo crecimiento del PIB en el primer trimestre del presente año, el 2 de junio, el Gobierno nacional, teniendo en cuenta el retroceso del sector de la construcción en el trimestre (1,4 por ciento), anunció, además de la continuación de los estímulos a la vivienda social, el subsidio consistente en 2,5 puntos en la tasa de interés para la compra de vivienda nueva por la clase media, ya sea de casa o apartamento, por un precio entre 99 y 321 millones de pesos.

Como se puede apreciar, a pesar de los programas implantados por el Gobierno para reactivar la economía, el descenso del PIB se debe a causas externas e internas: entre las primeras se puede mencionar la caída de los precios del petróleo y la situación que viven nuestros principales socios comerciales, en particular, Venezuela y Ecuador; sobre todo el primero, que por la crisis económica, social y política, redujo sus compras de 6.200 en 2008 a 600 millones de dólares en 2016. Además, el comportamiento de la economía mundial no es el mejor como para esperar que las exportaciones crezcan. En cuanto a las causas de origen interno, resalta el manejo de la política monetaria por parte del Banco de la República, con el fin de alcanzar la meta de inflación. Esta política ha sido contraccionista, debido a que consideró que la inflación era de demanda, cuando fueron factores de oferta los que presionaron los precios, sacrificándose así el crecimiento económico y la generación de empleo. Por su parte, el incremento del IVA disminuyó también la capacidad adquisitiva de la población y redujo los niveles de consumo.

Luis E. Vallejo Zamudio Director Revista Apuntes del Cenes 